\title{
CARACTERIZACIÓN Y TIPIFICACIÓN DE LOS SISTEMAS DE PRODUCCIÓN DE GULUPA (Passifora edulis f. edulis Sims) EN LAS REGIONES NORTE Y CENTRO - OCCIDENTE DE TOLIMA
}

\author{
CHARACTERIZATION AND TYPIFICATION OF PURPLE PASSION FRUIT \\ (Passifora edulis f. edulis Sims) PRODUCTION SYSTEMS, IN TOLIMA \\ NORTHERN AND CENTRAL-WESTERN REGIONS
}

Eleonora Rodríguez-Polanco • Irodriguezp@agrosavia.co

Ph D. Fitopatologia. Corporación Colombiana de Investigación Agropecuaria AGROSAVIA. C.I. NATAIMA. Colombia.

\begin{abstract}
Paula Bermeo Fúquene • pbermeo@agrosavia.co
Ingeniero Agrónomo. Corporación Colombiana de Investigación Agropecuaria AGROSAVIA. C.I. NATAIMA. Colombia.
\end{abstract}

José Segura-Amaya・jsegura@agrosavia.co

Tecnólogo Agrícola. Corporación Colombiana de Investigación Agropecuaria AGROSAVIA. C.I. NATAIMA. Colombia.

Edinson Parra-Alferes • ebayardo@agrosavia.co

Ingeniero Agrónomo. Corporación Colombiana de Investigación Agropecuaria AGROSAVIA. C.I. NATAIMA. Colombia.

Citación: Rodríguez-Polanco, E., Bermeo, P., Segura-Amaya, J., Parra-Alferes, E. (2022). Caracterización y tipificación de los sistemas de producción de gulupa (Passifora edulis f. edulis Sims) de las regiones Norte y Centro - Occidente de Tolima. Revista de Investigación Agraria y Ambiental, 13(1), 89 - 107.

DOI: https://doi.org/10.22490/21456453.4583

\section{RESUMEN}

Contextualización: La gulupa es una de las frutas exóticas con mayor demanda en el mercado internacional y es el tercer fruto que más exporta el país. El departamento de Tolima incrementó el área de cultivos de gulupa en un $61 \%$, del 2015 al 2019, lo que indica la progresiva importancia económica del cultivo en el departamento.

Vacío de conocimiento: A pesar de lo anterior, no se evidencian estudios de caracterización y/o tipificación de los productores, lo que limita una adecuada orientación de las políticas públicas de inversión, investigación y transferencia de tecnología. En consideración con esta situación, este estudio tuvo como objetivo caracterizar y tipificar los sistemas de producción de gulupa, teniendo en cuenta los aspectos productivos, tecnológicos y sanitarios vinculados al cultivo en los principales municipios productores de las regiones Norte y Centro-Occidente del departamento de Tolima.

Metodología: Con este propósito se diseñó y aplicó una encuesta estructurada para la captura de la información. La caracterización de los productores se realizó mediante análisis multivariado empleando análisis de correspondencia múltiple (ACM). La agrupación se llevó a cabo a través de análisis clúster, utilizando la distancia euclidiana y el método de Ward.

Resultados y conclusiones: En general, los resultados revelaron un nivel tecnológico bajo-alto asociado a la producción de gulupa en el departamento. 
Se identificaron dos grupos de productores. El Grupo I (GI) agrupó los productores ubicados principalmente en Cajamarca y Casabianca con un nivel tecnológico alto y con empleo de buenas prácticas agrícolas (BPA), el Grupo II (GII) agrupó a los productores ubicados principalmente en Santa Isabel y Rovira con un nivel tecnológico bajo y uso deficiente de BPA. El empleo de sistema de riego y cubierta plástica fueron identificadas como las practicas tecnológicas asociadas al grado de tecnificación del cultivo de gulupa en el Tolima. Los niveles de incidencia de la marchitez vascular (Fusarium oxysporum) alcanzaron valores entre el $4 \%$ al $59 \%$ en los principales municipios productores, constituyéndose así en una potencial limitante sanitaria para la sostenibilidad en el tiempo del agronegocio de gulupa en el departamento.

Palabras clave: Análisis de conglomerado; análisis de componentes principales; Passiflora edulis f. edulis Sims; tipología de fincas

\section{ABSTRACT}

Contextualization: The highest demand in the international market is exhibited by purple passion fruit, known as gulupa, which is the third most exported fruit in Colombia. Tolima department had increased $61 \%$ of gulupa crop area from 2015 to 2019, which demonstrates progressive economic importance of the crop in the zone.

Knowledge gap: However, characterization and typification farm assessments are not evidenced, that limits an adequate orientation of public investment, research, and technology transfer policies.

Purpose: Furthermore, to know the productive, technological, and health aspects associated to cultivation in the main producing municipalities of Tolima department was the aim of this study.

Methodology: Thus, a structured survey was designed and applied to capture farm information. The characterization of the producers was carried out by multivariate analysis, using multiple correspondence analysis (MCA). Clustering was realized through cluster analysis, using the Euclidean distance and Ward's method.

Results and conclusions: Overall, a low-high technological level associated with gulupa production in Tolima was revealed. Two groups of producers were identified. group I (GI) clustered producers located mainly in Cajamarca and Casabianca with a high technological level and employing good agricultural practices (GAP). Farmers located mainly in Santa Isabel and Rovira with a low technological level and poor use of BPA were arranged in group II (GII). The use of an irrigation system and plastic cover were identified as modern technological practices of gulupa crop in Tolima. Incidence levels (between $4 \%$ to $59 \%$ ) of vascular wilt (Fusarium oxysporum) in the main producing municipalities were observed, establishing potential sanitary limitation for gulupa agribusiness sustainability in Tolima over time.

Keywords: Cluster analysis; Passiflora edulis f. edulis Sims; principal component analysis; farm typology 


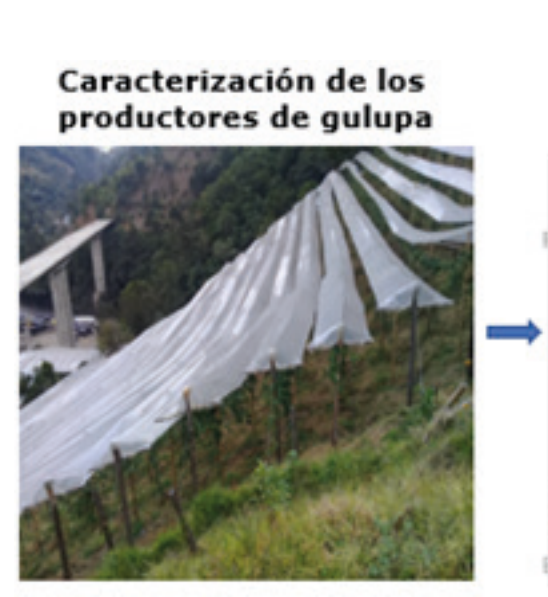

\section{Tolima - Colombia}

Zona de estudio: Tolima

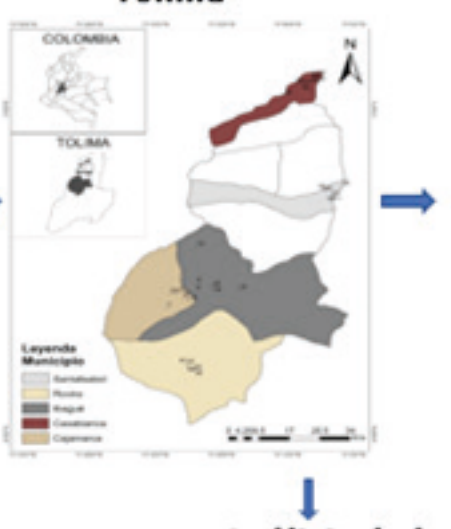

Análisis de la

información

- Análisis de correspondencia múltiple (ACM)

- Análisis de clúster

- prueba chi-cuadrado (Chi-q)

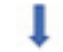

\section{Resultados}

Nivel tecnológico alto-bajo en la producción de gulupa. Dos grupos de productores, GI: Cajamarca y Casabianca, nivel tecnológico alto y empleo de buenas prácticas agricolas (BPA), GII: Santa Isabel y Rovira, nivel tecnológico bajo y uso deficiente de BPA.

\section{Diseño y aplicación de la encuesta}

Aspectos socioeconómicos y tecnológicos consultados a agricultores de gulupa (Passiflora edulis f. Edulis); y monitoreo en campo de la incidencia de enfermedades

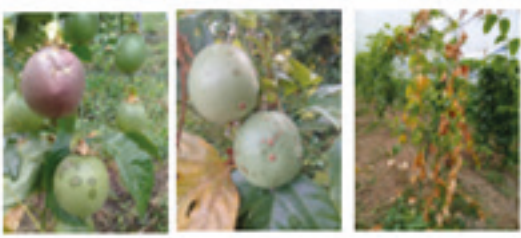

Fuente: autores

\section{INTRODUCCIÓN}

La gulupa (Passiflora edulis f. edulis Sims) o fruta de la pasión púrpura pertenece a la familia passiflorae, en la que el género pasiflora está caracterizado como el más importante, con alrededor de 530 especies distribuidas en América y en menor proporción en el sudeste tropical y subtropical de Asia, Australia y Nueva Zelanda (Ocampo y Wyckhuys, 2012). La gulupa está posicionada en un lugar preferencial dentro del mercado internacional, debido a su naturaleza exótica, excelentes propiedades organolépticas y alto contenido de compuestos bioactivos (Dhawan et al., 2004; Fischer \& Rezende, 2008; Portafolio, 2020).

La producción comercial de gulupa en Colombia se encuentra entre los 1.400 y 2.200 msnm. En altitudes mayores, la producción inicia entre los 12 a 18 meses y el tamaño de la fruta se reduce (Miranda et al., 2009). En altitudes de 1.200 a 1.500 msnm, la vida útil del cultivo es de 8 años, por el contrario, a los 800 msnm la viabilidad económica de la plantación es de 3 a 4 años (Nakasone \& Paull, 1998). Para el país, las temperaturas óptimas para el cultivo están en el rango de $15^{\circ} \mathrm{C}$ a $20^{\circ} \mathrm{C}$ (Jiménez et al., 2009). En general, las pasifloráceas requieren una precipitación bien distribuida durante todo el año, por lo que no crecen bien dada la falta de suministro de riego adicional (Fischer, 2010). Como límite pluviométrico inferior para cultivos de granadilla y el fruto de la pasión púrpura (gulupa) se sugieren zonas con un mínimo de $900 \mathrm{~mm}$ de precipitación anual uniformemente distribuida (Lüdders, 2003).

Dentro de la producción nacional se pasaron de exportar $4144 \mathrm{t}$ netas en el periodo de 2017 a exportar 5497 t en el 
mismo periodo de 2018, registrando un crecimiento de 32,6\% (Agudelo, 2019). Para este año, la producción y el rendimiento nacional de gulupa fue de 24,798 t y 16,55 t/ha respectivamente, destacándose el departamento de Antioquia como principal productor con 13,161 t y un rendimiento de 24,74 t/ha. Esto debido a la tecnificación del cultivo (Ministerio de Agricultura y Desarrollo Rural [Minagricultura], 2019). Le siguen los departamentos de Boyacá, Cundinamarca y Tolima, este último reportado con baja productividad $(1970 \mathrm{t})$ y rendimiento $(5,76 \mathrm{t} /$ ha) ( Minagricultura, 2019). En Tolima, estas explotaciones corresponden a economías campesinas, realizadas con mano de obra familiar. Sin embargo, no existe claridad de las limitantes tecnológicas que pueden estar originando la baja competitividad del cultivo de gulupa en el departamento.

En el país existe una amplia brecha tecnológica entre el conocimiento técnico y su adopción en las diferentes regiones productoras de gulupa, en las que, inclusive, las características de adaptación de la planta han sido poco estudiadas (Ocampo y Wyckhuys, 2012; Rodríguez et al., 2019). Las bajas producciones del cultivo son ocasionadas por diversos factores, entre estos los siguientes: exigencia del mercado asociada con la alta calidad del producto (Ramírez et al., 2017), escasa tecnificación, poca asociatividad entre productores, limitada transferencia tecnológica y problemas fitosanitarios.

En Colombia, las enfermedades constituyen un grave problema para la producción de gulupa al ocasionar pérdidas en cantidad y calidad de la fruta, las que pueden llegar a ser muy altas cuando existen condiciones ambientales que favorecen el desarrollo de los patógenos. Por ejemplo, enfermedades como la roña (Cladosporium cladosporioides) pueden reducir entre un $20 \%$ a $40 \%$ de la producción en presencia de condiciones ambientales favorables para su desarrollo, tales como: lluvias periódicas y prolongadas, densidades de siembra superiores a 850 plantas/ha y alta humedad relativa (>80 \%) (Ocampo y Wyckhuys, 2012).

Una situación similar ocurre con la mancha aceitosa (Xanthomonas axonopodis pv. passiflorae), que reduce considerablemente la productividad del cultivo. Las condiciones ambientales favorables, como mayor altitud y precipitaciones, permiten el incremento del inóculo bacteriano, que puede llegar a extenderse desde las hojas hasta los tallos y frutos (Benítez y Hoyos, 2009; Deshmukh et al., 2017). En suelos con drenaje limitado, el exceso de humedad favorece el desarrollo de enfermedades radicales, como la marchitez vascular (causada por el hongo Fusarium oxysporum), que pueden causar una destrucción total del cultivo. Es por esto que terrenos con textura arcillosa obligan a la construcción de drenajes superficiales que impidan la acumulación de aguas lluvias o de riego en el cuello de la raíz (Chacón, 1995), limitando la dispersión del hongo.

Con el propósito de atender los problemas señalados se han implementado métodos para estudiar las características de de los productores y de los lugares de producción. Una de las herramientas que permite agrupar los productores por características comunes de manejo, producción y tecnificación de un cultivo es la tipificación (Escobar et al., 2019). Los estudios de tipificación o caracterización de los sistemas de producción agrícola son necesarios e importantes porque permiten identificar grupos de productores dentro de la heterogeneidad de condiciones socioeconómicas y productivas. Por lo que se constituye en i) herramienta de consulta y guía para las entidades gubernamentales y tomadores de decisiones para orientar las políticas públicas, ambientales e inversiones y ii) programas de investigación y transferencia de tecnología que se ajustan a las circunstancias, limitaciones y posibilidades de los grupos de productores identificados (Correa et al., 2010; Escobar y Berdegué, 1990; Santos et al., 2013).

Por su parte, las técnicas estadísticas multivariadas son usadas para el estudio de tipología y caracterización de fincas (Andersen et al., 2007; Guto et al., 2012; Köbrich et al., 2003). Estas técnicas estadísticas permiten crear tipologías de fincas, particularmente cuando se dispone de una extensa base de datos. El empleo del análisis de componentes principales (ACP), por ejemplo, reduce las dimensiones de las tablas de contingencia y proporciona una representación gráfica de la información contenida en estas tablas, además de un nuevo espacio de factores independientes en el que las categorías similares de diferentes variables aparecen 
más cercanas (Hernández-Castellano et al., 2019; Instituto Nacional de Estadística y Geografía [INEGI], 2013; Toro-Mujica et al., 2015). El ACP permite detectar los factores (dimensiones) que mejor caracterizan las fincas.

Empleando los factores del ACP se puede realizar una agrupación de individuos, de tal manera que cada grupo esté compuesto por unidades homogéneas, y los grupos entre estas sean muy heterogéneos. En la agrupación se pueden emplear métodos como el de Ward utilizando la distancia euclidiana (Köbrich et al., 2003). La única técnica de agrupamiento jerárquico que basa su funcionalidad en un criterio de suma regular de cuadrados es el método de Ward, el cual permite obtener grupos definidos y minimizar la dispersión de cada elemento en cada grupo producido (Murtagh \& Legendre, 2014). La medición de distancias, a través de software especializado, genera dendrogramas que muestran la similitud o disimilitud entre grupos definidos.

A nivel microeconómico, la clasificación de agricultores podría ser de utilidad práctica para soluciones tecnológicas localizadas y apoyo de extensión, al constituir grupos de agricultores cuyas circunstancias son lo suficientemente similares para ser elegibles con la misma recomendación tecnológica (Harrington \& Tripp, 1984). Los estudios de caracterización de productores, por otra parte, son necesarios a la hora de diseñar tecnologías orientadas al entorno y condiciones específicas de los tipos de productores, facilitando así la adopción de estas. En este sentido, el desconocimiento de los elementos vinculados a la producción de gulupa en el departamento de Tolima es un limitante para mejorar la competitividad y productividad de este cultivo en el departamento.

Teniendo en cuenta lo anterior, esta investigación planteó la hipótesis de que la producción de gulupa en el departamento de Tolima se realiza con diferentes niveles tecnológicos y presenta diferente grado de afectación por enfermedades. Estos niveles deben ser determinados para formular recomendaciones tecnológicas que respondan a las necesidades de los diferentes grupos de productores. En consecuencia, el objetivo de la investigación fue identificar las tecnologías de producción, prácticas agronómicas y enfermedades predominantes en cultivo de gulupa del departamento de Tolima, para así generar una línea de base del sistema productivo como insumo para formular proyectos de investigación y transferencia de tecnología.

\section{MATERIALES Y MÉTODOS}

\section{Caracterización del sistema productivo de gulupa}

La investigación se realizó en el segundo semestre de 2019, en los cinco municipios con mayor área establecida de gulupa en el departamento de Tolima: Cajamarca, Ibagué (Corregimientos Tapias y Toche), Santa Isabel, Casabianca y Rovira (corregimiento de Riomanso), (Figura 1). Los aspectos relacionados con las características tecnológicas, sanitarias y productivas de los productores fueron estudiados mediante la aplicación de una encuesta estructurada para este propósito (Tabla 1).

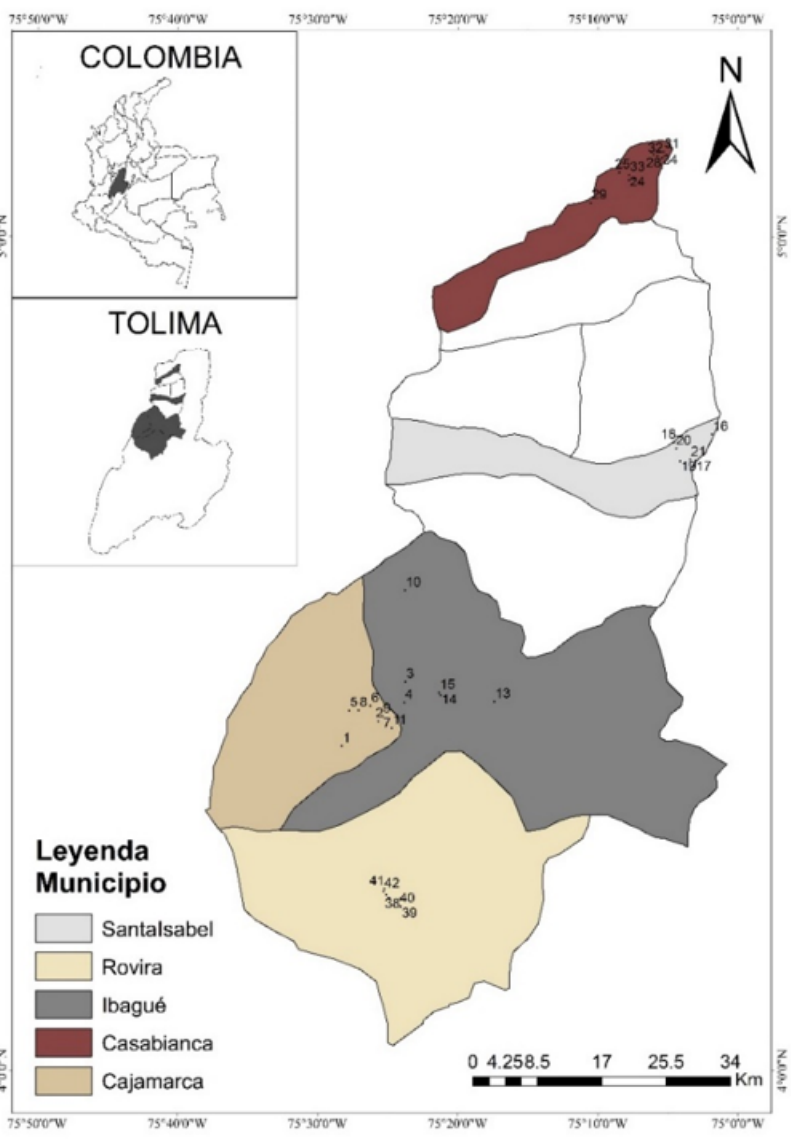

Figura 1. Ubicación geoespacial de las fincas productoras de gulupa encuestadas y enumeradas en los municipios de mayor área del cultivo en el departamento de Tolima. Fuente: autores. 
El tamaño de la muestra se estableció mediante un diseño muestral aleatorio simple, sin reemplazo, considerando la varianza máxima según la Ecuación 1:

$$
n=\frac{N \cdot Z_{\propto / 2}^{2} \cdot p \cdot(1-p)}{(N-1) \cdot \varepsilon^{2}+Z_{\propto / 2}^{2} \cdot p \cdot(1-p)}
$$

\section{Donde:}

$\mathrm{N}=$ población total

$\mathrm{Z}^{2} \infty / 2=$ Valor de la distribución normal estándar para un nivel de confianza del $90 \%$ (1645)

$\mathrm{p}=$ valor de la proporción a priori de la varianza máxima de una variable de proporción $(0,5)$ $\varepsilon=$ error máximo permitido de la estimación del $13 \%(0,13)$

$\mathrm{n}$ = tamaño de la muestra
Para este estudio, el tamaño de la población ( $\mathrm{N}$ ) se expresó como el número de productores de gulupa en el departamento de Tolima, el cual fue determinado por el cociente obtenido del informe oficial más reciente del área plantada en gulupa en el departamento (440 ha), (Minagricultura, 2018) con un área de plantación promedio de gulupa ( $\approx 1$ ha), lo que correspondería a 440 productores aproximadamente. Asimismo, los valores considerados para $Z^{2} \infty / 2, p y$ $\varepsilon$ fueron $90 \%$ (1.645), 0,5 y $13 \%(0,13)$ respectivamente. Se obtuvo un tamaño de muestra de 42 productores. El tamaño de muestra por municipio fue: Cajamarca (11), Ibagué (corregimiento Tapias y Toche) (4), Santa Isabel (6), Casabianca (13) y Rovira (corregimiento de Riomanso) (8), (Figura 1).

Tabla 1. Aspectos socioeconómicos y tecnológicos consultados a agricultores de gulupa (Passiflora edulis f. edulis) en una encuesta realizada en las zonas productoras del departamento de Tolima.

\section{Variable}

\subsection{Manejo integrado del} cultivo

Control de arvenses Tipo de fertilización Control de plagas
Control físico de arvenses

Fertilización química

Frecuencia de aplicación de insecticidas* (PesticidaFrec)

Plaga principal Nombre 1. Aspectos socioeconómicos

1.1. Entorno social 1. 2. Entorno productivo Localización Unidad productiva

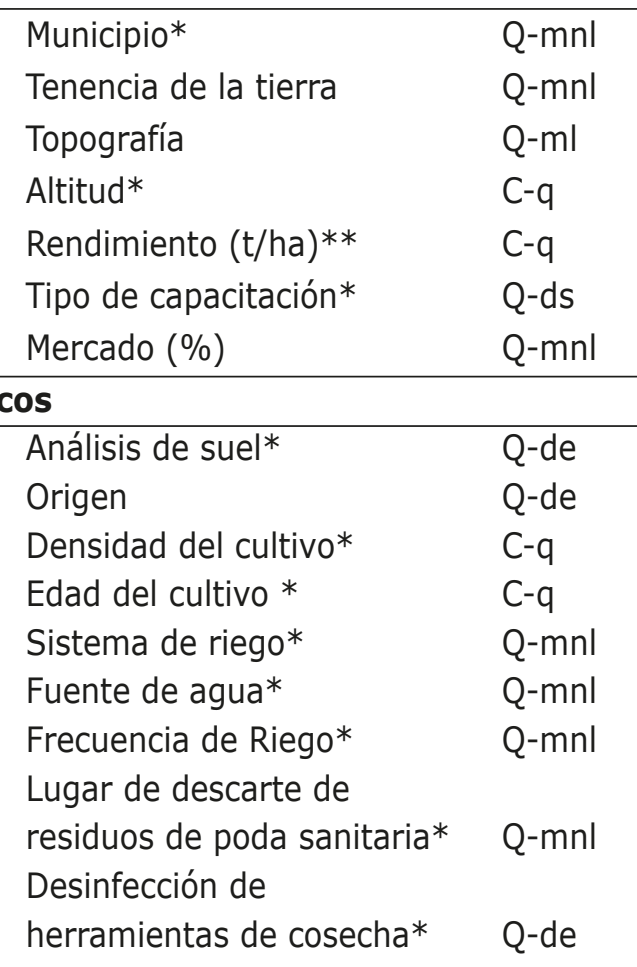

Tipo+

Q-mn

$C-q$

Entorno de capacitación Tipo de capacitación* Q Q-ds

\section{Aspectos tecnológicos}

2.2. Semilla

2.3. Siembra

2.4. Irrigación

2.5 Prácticas agrícolas 
Control de enfermedades

\subsection{Prácticas de poscosecha}

Frecuencia de aplicación de

fungicidas*(FungicidaFrec)

Q-mnl

Principal enfermedad*

Q-ml

ncidencia de Fusarium*

Q-ml

Total enfermedades*

C-q

Semi-cubierta*

Q-de

Clasificación*

Q-mnl

Variables sin asterisco, no se consideraron debido a que presentaban variación menor al $13 \%$. *Variables utilizadas para el análisis de componentes principales. **No se consideró debido a falta de información del $35 \%$ de las encuestas. +Q-de: doble estado cualitativo; Q-mnl: multiestado cualitativo, no lógico; Q-ml: multiestado cualitativo, lógico; C-q: cualitativo continuo.

Fuente: Autores.

La encuesta se dividió en dos secciones asociadas con el aspecto socioeconómico y tecnológico e incluyó 27 variables que se categorizaron de acuerdo con las respuestas de los productores (Tabla 1). Para el análisis de los datos se descartaron las variables que presentaron variación menor al $13 \%$ como: tenencia de la tierra (propia en un $90,5 \%$ ), topografía (escarpada 95,2 \%), origen de la semilla (vivero 78,6\%), manejo de la fertilización (química 97,6 \%), control de arvenses (guadaña 95,23\%), área con gulupa $(0,4$ a 2 ha $78,6 \%)$, y el tipo de mercado (exportador $100 \%$ ). Dentro del aspecto productivo no se consideró el rendimiento (t/ha) debido a que el $35 \%$ de la muestra (15 predios) se encontraban aún en fase de crecimiento y no había iniciado la fase reproductiva.

Las 16 variables cualitativas empleadas en el análisis fueron: municipio, tipo de riego, frecuencia de riego, fuente de riego, análisis de suelos, principal enfermedad, frecuencia de aplicación de fungicidas, frecuencia de aplicación de insecticidas, disposición de residuos de la poda, tipo de capacitación, uso de semitecho, desinfección de herramientas en cosecha, selección de fruta para exportación, densidad de plantas, edad de las plantas e incidencia de Fusarium. Las tres variables cuantitativas fueron la altitud, el área en gulupa y el total de enfermedades (Tabla 1).

\section{Incidencia de enfermedades}

Se determinó la incidencia de enfermedades foliares y de fruto en gulupa [mancha aceitosa (Xanthomonas axonopodis pv. passiflorae), roña (Cladosporium cladosporioides) y antracnosis (Colletotrichum gloeosporioides)]. Para esto en cada predio y dentro del cultivo se realizó un muestreo sistemático tipo grilla, estableciéndose 30 unidades de muestreo (planta de gulupa) en un área aproximada de $2.250 \mathrm{~m}^{2}$, separadas $20 \mathrm{~m}$ dentro de los surcos y 7,5 m entre los surcos; el área de cada unidad de muestreo fue de un metro cuadrado (Mora, 2011). En cada unidad de muestreo fueron contados total de frutos sanos, total de frutos afectados por mancha aceitosa y total de frutos afectados por roña.

Por su parte, la incidencia de la marchitez vascular (Fusarium oxysporum) fue estimada en un área de media hectárea, considerando plantas afectadas con relación al total de plantas en media hectárea (1.100) y empleando la escala desarrollada por Osorio et al. (2020) (alta: > 31\%; media: 20-30 \%; baja: 1-19 \% y ausente: $0 \%$ ). El patrón de distribución de la secadera, como también se le conoce, se categorizó de la siguiente forma. Aislado: presencia de pocas plantas individuales afectadas dentro del cultivo; focos: presencia de uno o varios grupos de plantas con presencia de síntomas; generalizado: se observa más del $80 \%$ de plantas dentro del cultivo con presencia de síntomas.

\section{Análisis estadístico}

La caracterización de los productores se realizó mediante análisis multivariado empleando análisis de correspondencia múltiple (ACM). La agrupación se llevó a cabo a través de análisis clúster, utilizando la distancia Euclidiana y el método de Ward. Para identificar las variables con mayor correlación generadas en el ACM se utilizó la función dimdesc con el empleo de la razón de correlación al cuadrado $\left(\mathrm{R}^{2}\right)$ en el paquete FactoMineR (Lê et al., 2008). Posteriormente, 
se realizaron tablas de contingencia entre las variables y los grupos generados, y se utilizó la prueba chi-cuadrado (Chi-q) para determinar diferencias estadísticas entre los grupos. Todos los datos se analizaron con el software estadístico Rstudio versión 1.2.5042 (R project versión 3.5.3).

Para la incidencia de las enfermedades foliares y de raíz-tallo se tuvieron en cuenta dos factores: i) la localización o municipio: Santa Isabel, Ibagué, Cajamarca, Rovira y Casabianca; y ii) el tipo de enfermedad: mancha aceitosa, roña y marchitez vascular. La interacción de estos factores generó un total de 15 tratamientos, en los que la incidencia de la enfermedad fue la variable de respuesta, según la ecuación 2 :

Incidencia $(\%)=$ (número de frutos o plantas con síntomas/número total de frutos o planta observadas) $* 100$

Los totales de frutos sanos y total de frutos enfermos, para el caso de bacteriosis y roña, se usaron como variables independientes; y la cantidad de plantas enfermas y plantas sanas, como variables independientes para el caso de la marchitez vascular. Debido a que los datos no mostraron una distribución normal, éstos se analizaron mediante un modelo lineal generalizado (GLM).

Al asumir que cada infección ocurrió de manera independiente entre los frutos 0 plantas y que la probabilidad de infección se mantuvo constante durante la colecta de los datos, la distribución que mejor se ajustó a la variable de respuesta fue la binomial (con logit como función de enlace) (Di Rienzo et al., 2012), con parámetros $n$ desconocido y $\mathrm{n}=30$. Para comparar las diferencias entre las medias se utilizó la prueba de LSD Fischer $(P<0,05)$. Todos los datos se analizaron con el software estadístico Rstudio versión 1.2.5042 ( $\mathrm{R}$ project versión 3.5.3).

\section{RESULTADOS Y DISCUSIÓN}

\section{Caracterización del sistema productivo de gulupa}

De acuerdo con el ACM, diez componentes se obtuvieron, los cuales explicaron un 73,69 $\%$ del total de la varianza acumulativa del análisis. Los dos primeros componentes explican el $19,59 \%$ y $10,7 \%$ de esta varianza, respectivamente. El primer componente fue caracterizado por la variable cuantitativas «total de enfermedades» (correlación 0,54; $\mathrm{P}<0,001) ; \mathrm{y}$ por las cualitativas asociadas a riego: frecuencia de riego; fuente de riego y municipio $\left(\mathrm{R}^{2}=0,88 ; 0,87 ; 0,86\right.$ y 0,81 ; respectivamente, con $P<0,001$ para todos); densidad de siembra; semicubierta; residuos de poda y análisis de suelos $\left(R^{2}=0,44\right.$; 0,$4 ; 0,43$ y 0,27 ; respectivamente, con $P<$ 0,001 para todos); frecuencia de aplicación de insecticidas; capacitaciones; clasificación de la fruta; incidencia de Fusarium; edad del cultivo y desinfección de herramientas $\left(R^{2}=0,26 ; 0,19 ; 0,22 ; 0,25 ; 0,11\right.$ y 0,1 respectivamente y con $P<0,05$ para todos).

El segundo componente fue explicado por la variable cuantitativa «área de gulupa» $\left(R^{2}=0,5 ; P<0,001\right)$. Dentro de las variables cualitativas que explican el agrupamiento se encuentran: el municipio; la incidencia de Fusarium; tipo de riego; la frecuencia de riego; la frecuencia de insecticidas $\left(R^{2}=0,61\right.$; 0,$59 ; 0,5 ; 0,33$ y 0,3 respectivamente y con $P<0,001$ para todos); la edad del cultivo; desinfección de herramienta; la principal enfermedad y el análisis de suelos $\left(R^{2}=0,13\right.$; 0,$13 ; 0,21$ y 0,1 ; respectivamente, con $P<$ 0,05 para todos) (Figura 2).

Igualmente, dentro de las categorías representativas en el componente uno, se encuentran las características: fincas sin uso de tecnologías de riego (sin sistema de riego), municipio de Rovira, densidades de siembra menor de 2.000 plantas/ha, residuos de poda dentro del lote, semitecho, análisis de suelos, frecuencia de insecticidas semanal, selección de fruta por su sanidad u homogeneidad, capacitación de forma empírica, bacteriosis como principal enfermedad, bajas incidencias de marchitez vascular, edad del cultivo mayor a dos años y desinfección de herramientas de cosecha (Figura 2). Todas las categorías con $(P<0,05)$.

Dentro de las categorías representativas del segundo componente se encuentran: municipio de Santa Isabel, altas incidencias de marchitez vascular, otro tipo de riego, frecuencia de riego quincenal, aplicación de insecticidas semanal, marchitez vascular 


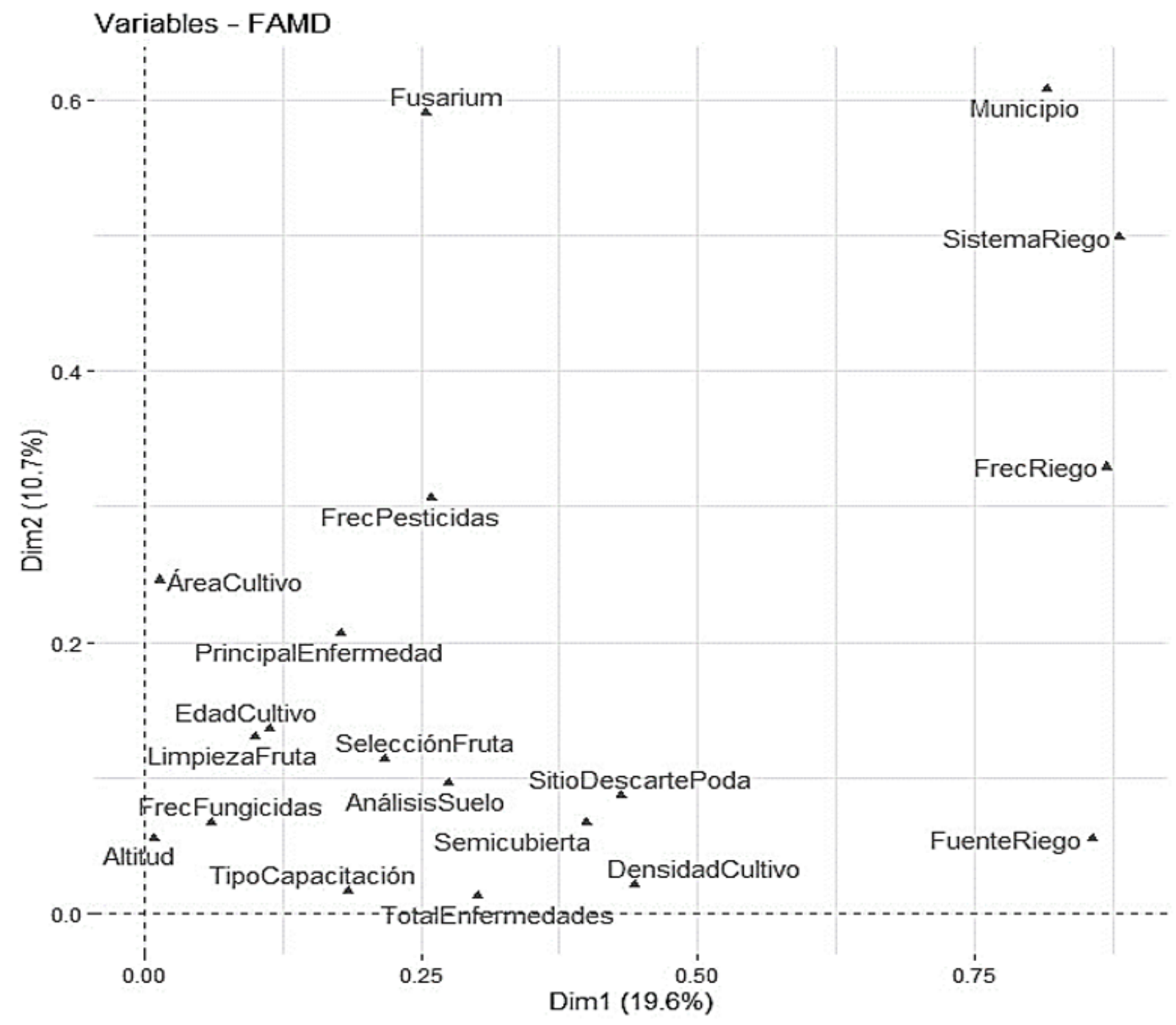

Figura 2. Resultados del análisis de correspondencia múltiple por variable de productores de gulupa encuestados en el departamento de Tolima. Mapa de factores que muestra las 19 variables que describen los dos primeros agrupamientos (Detalle de las variables en la Tabla 1 ).

Fuente: autores.

como principal enfermedad, edad del cultivo mayor a dos años, desinfección de herramientas, selección de la fruta por sanidad u homogeneidad y análisis de suelos (Figura 2). Todas las categorías con $(P<0,05)$.

El análisis multivariado de datos mixtos permitió la formación de dos conglomerados (GI y GII) de agricultores, lo que evidencia la existencia de divergencia dentro de los productores de gulupa en el departamento de Tolima (Figura 3). De acuerdo con Jiménez et al. (2017), este método permite relacionar variables de diferentes criterios (geográfico, manejo del cultivo y producción del cultivo), con el fin de generar agrupamientos que presentan características individuales, identificando así las problemáticas asociadas al sistema productivo y la focalización de esfuerzos para generar las estrategias eficientes para mejorarlas.

En el GI se encontraron el $64,3 \%$ de los predios de la muestra donde se realizan prácticas de tecnificación del cultivo: sistema de riego por goteo $(96,29 \%)$-con aplicación de este diario a semanal (92,6\%)y quebrada como fuente de agua $(62,96$ $\%)$. La mayor proporción de estas fincas se encuentra en el municipio de Casabianca $(48,14 \%)$ y Cajamarca $(37,7 \%)$ presentan las siguientes características: densidades de siembra superiores a 2000 plantas/ha $(88,8$ $\%)$, cubierta en semitecho $(62,96 \%)$, uso de 


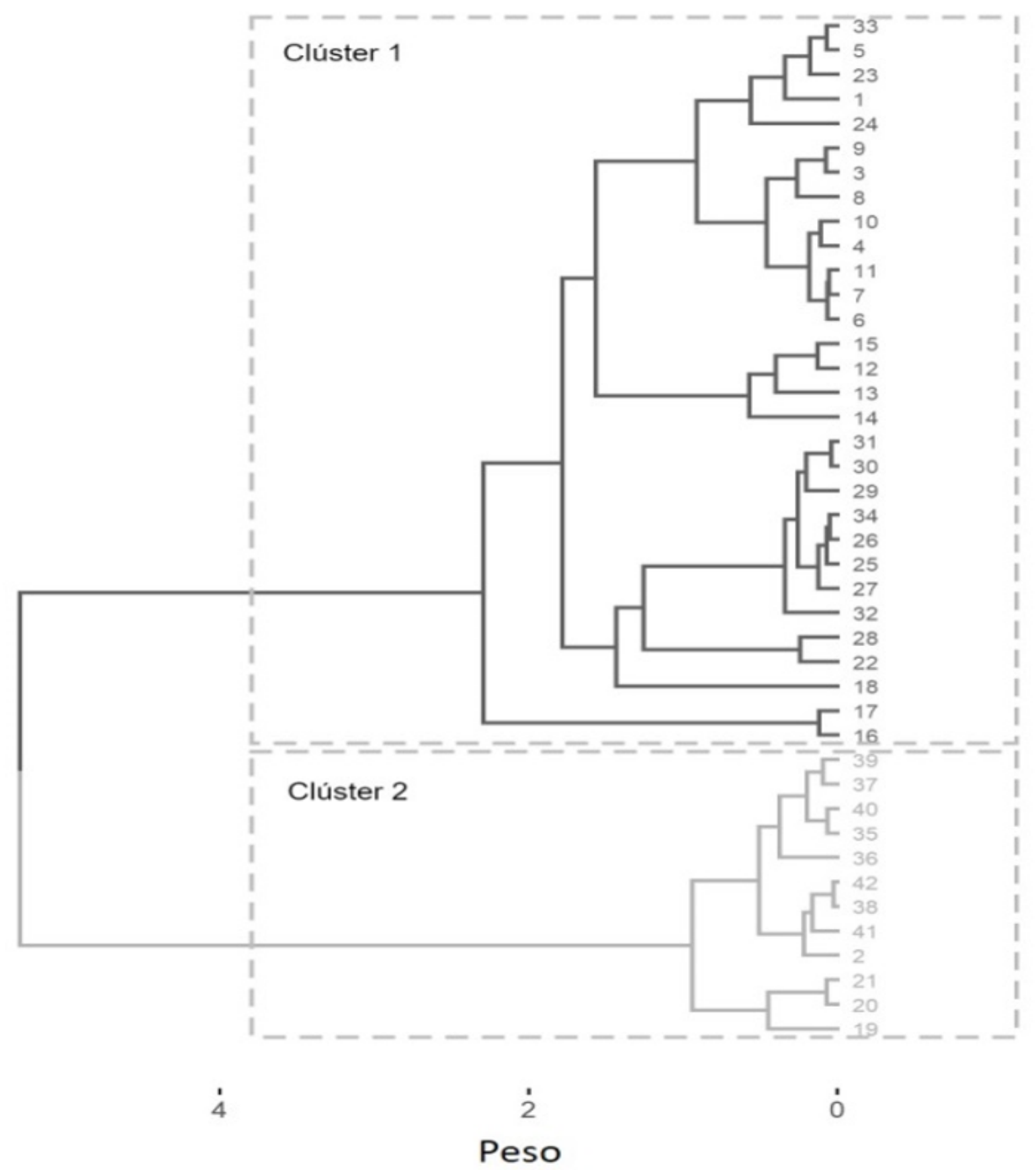

Figura 3. Conglomerados de productores de gulupa del departamento de Tolima, establecidos mediante análisis multivariados por el método de agrupamiento jerárquico de Ward.

Fuente: autores.

una fosa fitosanitaria $(74,07 \%)$, frecuencia de uso de insecticidas quincenal a mensual $(81,48 \%)$, selección de la fruta por tamaño $(55,5 \%)$, análisis de suelos $(74,07 \%)$, incidencias de marchitez vascular bajas $(40,74 \%)$ y sin desinfección de herramientas en cosecha $(66,66 \%)$ (Tabla 2$)$. En general, el GI está conformado por fincas localizadas en Casabianca y Cajamarca, caracterizadas por un grado de tecnificación alto, adopción de buenas prácticas agrícolas (BPA) y baja incidencia de marchitez vascular. 
Tabla 2. Descripción de las variables y sus categorías utilizadas para el análisis de grupos, a partir de encuestas a productores de gulupa en el departamento de Tolima.

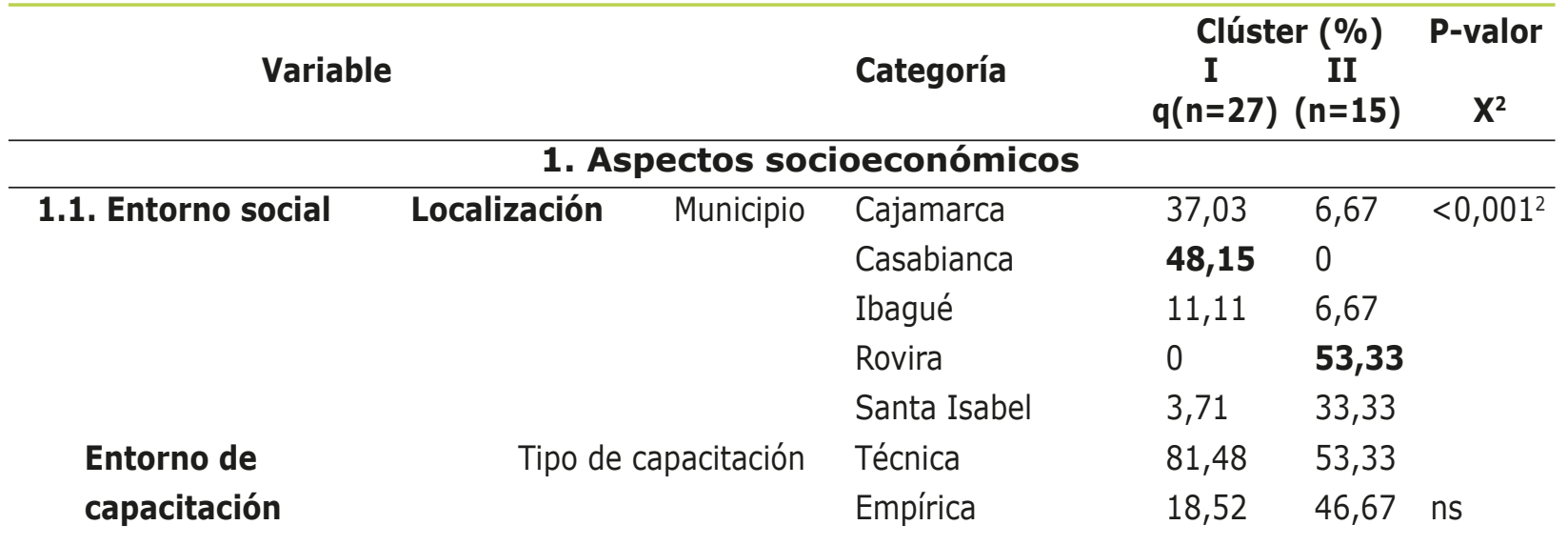

\section{Aspectos tecnológicos}

2.1. Suelo

2.3. Siembra

\subsection{Irrigación}

\subsection{Prácticas agrícolas}

Control de plagas
herramientas de cosecha
Frecuencia de

aplicación de insecticidas

\section{Control de enfermedades}

Frecuencia de

aplicación de

fungicidas
Con análisis reciente

menor 1 año

Sin análisis 0

mayor a 1 año

$74,07 \quad 43,34<0,01$

$\leq 2.000$ plantas ha $^{1}$

$25,93 \quad 66,66$

11,12

$66,66<0,001$

$\mathbf{8 8 , 8 8}$

33,34

77,78

53,33

NS

$22,22 \quad 46,67$

$>2$ años

96,29

$6,67<0,001$

Goteo

3,71

13,33

Sin riego

0

80

62,96

$6,67<0,001$

Otra fuente

(manantial)

$37,04 \quad 13,33$

No Fuente agua

0

Diario-semanal

$\mathbf{9 2 , 5 9}$

80

Quincenal-mensual

7,41

6,67

13,33

Sin Frecuencia riego 0

80

Residuo dentro

del lote

22,22

80

$<0,01$

Residuo en

fosa sanitaria

$\mathbf{7 4 , 0 7} 20$

No realiza poda

$3,71 \quad 0$

Con desinfección

33,34

$66,67<0,05$

Sin desinfección

66,66

33,33

Semanal

11,11

$\mathbf{5 3 , 3 3} 0,01$

Quincenal-mensual

81,48

46,67

No aplica

$7,41 \quad 0$

Semanal

22,22

46,67

NS

Quincenal-mensual

46,67

No aplica

66,66

6,66 


\begin{tabular}{|c|c|c|c|c|}
\hline Principal & Mancha aceitosa & 11,11 & 33,33 & NS \\
\hline enfermedad & Roña & 25,92 & 20 & \\
\hline & Marchitez vascular & & & \\
\hline & (Fusarium) & 48,14 & 46,67 & \\
\hline & Otra & 14,83 & 0 & \\
\hline Incidencia de Fusarium & Alto $>31 \%$ & & & \\
\hline (Osorio et al., 2020) & de incidencia & 3,7 & 33,33 & NS \\
\hline & Medio $20-30 \%$ & & & \\
\hline & de incidencia & 22,22 & 33,33 & \\
\hline & Bajo 1-19\% & & & \\
\hline & de incidencia & 40,74 & 33,33 & \\
\hline & Ausente 0\% & & & \\
\hline & de incidencia & 33,34 & 0 & \\
\hline Total de enfermedades & $\begin{array}{l}\text { Cantidad total } \\
\text { de enfermedades }\end{array}$ & & & \\
\hline & activas presentes & 1,86 & 2,74 & $<0,001$ \\
\hline Semi cubierta & Con semicubierta & & & \\
\hline & plástica en surcos & 62,96 & 6,67 & $<0,001$ \\
\hline & Sin semicubierta & & & \\
\hline & plástica en surco & 37,04 & 93,33 & \\
\hline Clasificación & Tamaño & 55,55 & 13,33 & $<0,01$ \\
\hline & Otra clasificación & 22,22 & 73,33 & \\
\hline & No clasifica & 22,23 & 13,34 & \\
\hline
\end{tabular}

1Porcentajes en negrilla representan los valores más altos significativos por categoría en cada clúster. $2 \mathrm{P}<0,05$ significativo, $\mathrm{P}<0,01$ muy significativo, $\mathrm{P}<0,001$ altamente significativo, NS: sin diferencia significativa.

Fuente: autores.

El GII con el 35,7 \% de los predios muestreados se caracterizó por no poseer sistema de riego (80 \%). La mayor proporción de estas fincas se encuentra ubicada los municipios de Rovira (53,33 \%) y Santa Isabel $(33,33 \%)$, y tienen estas características: densidades de siembra menores a 2.000 plantas/ha $(66,66 \%)$, sin cubierta en semitecho $(93,33 \%)$, disposición de los residuos de poda en el lote $(80 \%)$, frecuencia de insecticidas semanal (60\%), selección de la fruta por sanidad y homogeneidad $(73,33 \%)$, sin análisis de suelos $(66,66 \%)$, y con desinfección de herramientas en cosecha $(66,66 \%)$ (Tabla 2). En su mayoría, el GII está conformado por fincas localizadas en Rovira y Santa Isabel que se caracterizan por la baja tecnificación y la aplicación de BPA en el cultivo.

De acuerdo con el consolidado de MinAgricultura (2018), el municipio de
Rovira presentó los rendimientos más bajos en el departamento de Tolima con 3 t/ha para el 2018; mientras que el municipio de Casabianca presentó para el 2018 un rendimiento de 25 t/ha, ubicándose como el principal productor en el departamento (MinAgricultura, 2018). Estos valores de producción corroboran la correlación positiva entre el grado de tecnificación del cultivo, que incluye el empleo de BPA, y la productividad debido al uso más eficiente de los recursos (Prieto, 2019). Los niveles más altos de adopción de tecnología están asociados con una mayor competitividad, sostenibilidad y viabilidad de las explotaciones.

En especies del género de pasifloras, como el caso de maracuyá (Passiflora edulis Sims.), los aspectos relacionados con la tecnificación del cultivo, como el incremento en la densidad de siembra, han mostrado un incremento en la producción sin afectar la 
calidad de los frutos (Moreira et al., 2017). Con relación al manejo de enfermedades, el empleo de cubierta o semitecho plástico ha $r$ demostrado ser útil para obtener una reducción en la incidencia y severidad de la mancha aceitosa y enfermedades fúngicas (Montoya et al., 2013), al disminuir la trasmisión de la luz visible. Esto afecta directamente a las proteínas fotosensibles a factores LOV (Luz, Oxígeno o Voltaje), presentes en el género Xanthomonas. Estas proteínas tienen implicaciones en la fisiología bacteriana al modular características directamente asociadas con su capacidad para colonizar la plantas hospederas como: motilidad, adhesión, formación de biofilm y resistencia al estrés oxidativo, mediante la síntesis de flagellum, exopolisacáridos y adhesinas (Da Silva et al., 2002; Kraiselburd et al., 2017).

Otras prácticas de cultivo, como la eliminación de partes enfermas de la planta y de los residuos de poda y de cosecha (Joy \& Sherin, 2016; Ocampo y Wyckhuys, 2012), así como la desinfección de herramientas durante la poda y cosecha (Benítez, 2010; Deshmukh et al., 2017; Joy \& Sherin, 2016; John Ocampo y Wyckhuys, 2012) y el uso de cultivares resistentes (Costa et al., 2018), contribuyen en el manejo de la mancha aceitosa y la roña disminuyendo así el detrimento que pueden causar en la producción.

Un estudio de caracterización del sistema productivo de gulupa para los departamentos de Boyacá y Cundinamarca, desarrollado por Miranda y Carranza (2010), indicó la existencia de dos sistemas: el primero se caracteriza por medianos productores, propietarios de la tierra, con suelos no mecanizados, economía campesina, con gulupa morada de tipo regional, disponibilidad de riego y venta de producto a intermediarios; el segundo grupo solo difería del primero por ser pequeños productores, con terrenos arrendados y no tener disponibilidad de sistema de riego.

Nuestros resultados coinciden en que el empleo de sistema de riego y la cubierta en semitecho está asociado con productores con mayor capacidad económica, lo que les permite a los productores mayor acceso a la tecnificación de su cultivo y empleo de BPA
(Tabla 2). Esto garantiza la obtención de fruta de primera calidad con fácil acceso al mercado de exportación. Lo contrario ocurre con el de los productores sin acceso estas tecnologías y aplicación de BPA, ya que obtienen mayor proporción de fruta para el mercado nacional, caracterizada por un precio hasta cinco veces inferior al del mercado exportador, llegando a hacer inviable su permanencia como productores de gulupa.

En un sistema agrícola el recurso hídrico hace parte esencial del funcionamiento de las plantas. En las especies frutícolas como las pasifloras, en las que la floración y la fructificación se presenta durante todo el año, se requiere de precipitación bien distribuida. Los requerimientos hídricos en gulupa y maracuyá se estiman entre 1300 a 1800 mm anuales, alcanzando producciones de 17 t/ ha con un $100 \%$ de evapotranspiración en suelo (Angulo, 2009; Guilherme et al., 2020; Ocampo et al., 2010). Cuando falta el agua en fases críticas del desarrollo productivo (como la brotación de yemas florales, fecundación, cuajado y llenado) los frutos se quedan pequeños o se caen (Jiménez et al., 2009), por lo que en regiones con mala distribución de lluvias es necesario establecer sistemas de riego en el cultivo que aseguren el buen desarrollo y calidad de la fruta.

\section{Incidencia de enfermedades}

La incidencia de las enfermedades foliares y de raíz-tallo, se analizó estadísticamente empleando el modelo lineal generalizado (GLM), con distribución binomial (logit) y la prueba de LSD Fischer para la comparación de medias. La incidencia de cada enfermedad se presentó como variable de respuesta. Se establecieron diferencias significativas $(P<0,05)$ para la incidencia de roña, mancha de aceite y secadera presente en los cultivos de gulupa de los municipios estudiados (Figura 4).

Se identificaron como las enfermedades más prevalentes en el cultivo de gulupa, en la región de Tolima: la roña (Cladosporium cladosporioides), la marchitez vascular (Fusarium oxysporum) y la mancha de aceite ( $X$. axonopodis pv. passiflorae). Sólo se observaron dos casos de infecciones similares a las de origen viral en el municipio de Casabianca y no se encontraron síntomas de infección por antracnosis (Figura 4). 


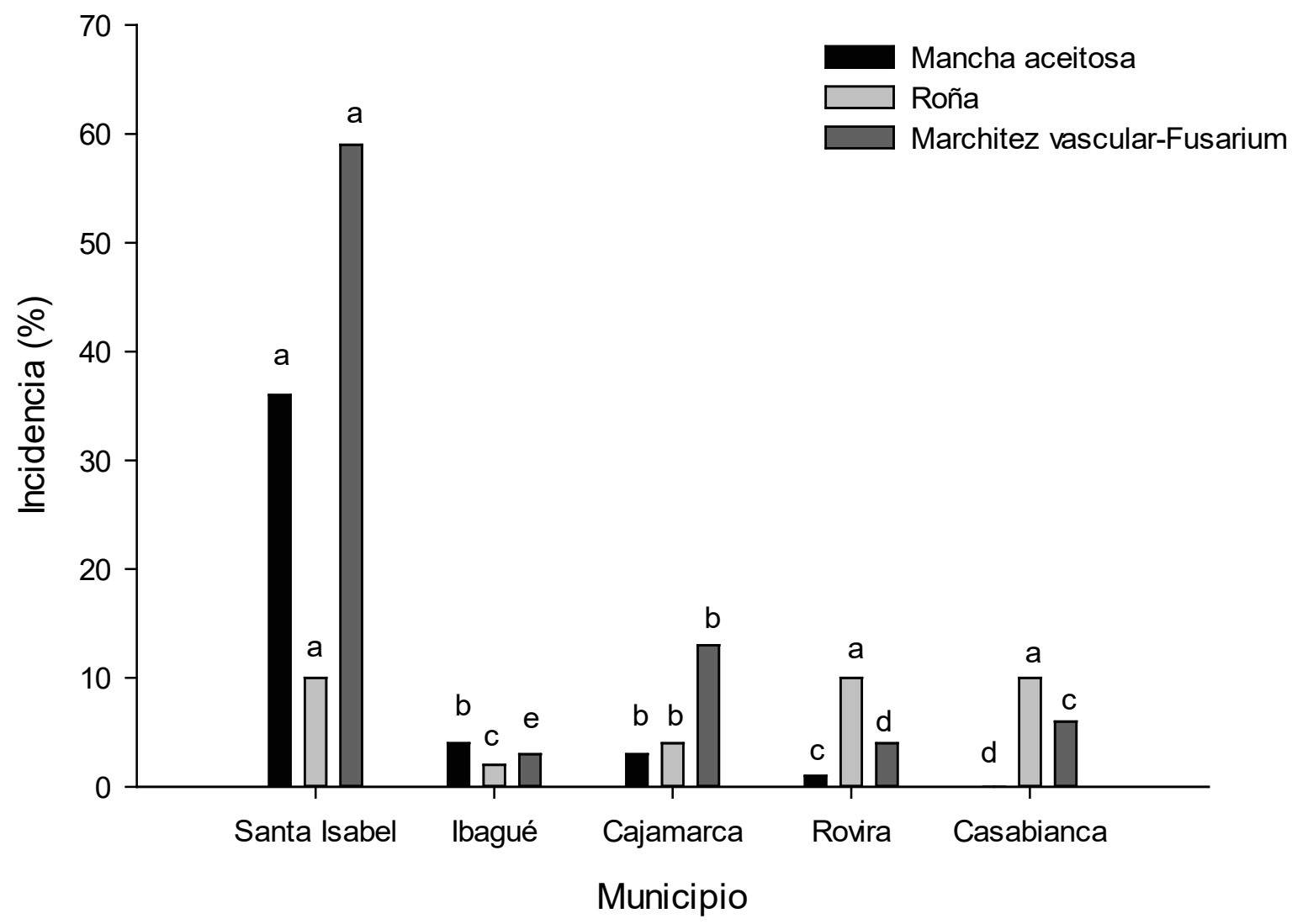

Figura 4. Incidencia de las enfermedades presentes en cinco municipios productores de gulupa del departamento de Tolima. Letras diferentes presentan significancia mediante el uso de la prueba de LSD Fischer $(P<0,05)$.

Fuente: autores.

La incidencia de la roña en frutos presentó los valores más altos en Santa Isabel, Rovira y Casabianca con $10 \%$ para cada una de las regiones y estadísticamente iguales $(P<0,05)$. Los valores más bajos y significativamente diferentes se observaron en Ibagué y Cajamarca con $4 \%$ y $2 \%$ respectivamente. El valor más alto de incidencia de bacteriosis en frutos fue del $36 \%$ en el municipio de Santa Isabel, estadísticamente diferente y seguido en orden decreciente por Ibagué, Cajamarca y Casabianca con valores del $4 \%$, $3 \%$ y $0 \%$ respectivamente e igual significancia estadística $(P<0,05)$ (Figura 4$)$. El valor más alto de incidencia de la marchitez vascular en plantas se presentó en Santa Isabel con un $59 \%$, seguido en orden decreciente por Cajamarca, Casabianca, Rovira e Ibagué con valores de $13 \%, 6 \%, 4 \%$ y $3 \%$ respectiva y estadísticamente diferentes entre sí $(P<0,05)$.

En general, las incidencias más altas de roña, mancha bacteriana y muerte vascular se observaron en Santa Isabel (Figura 4).
Los predios de este municipio se ubicaron en el GII, caracterizado por menor empleo de sistemas de tecnificación y BPA, cuya situación favorece el desarrollo de las enfermedades. La alta incidencia de bacteriosis puede también ser atribuida a la altitud a la cual se encuentra ubicado este municipio (1.548 msnm), donde las condiciones climáticas prevalentes (temperatura y humedad relativa de $22{ }^{\circ} \mathrm{C}$ y $80 \%$ respectivamente), unidas a la falta de cubierta o semitecho plástico en los surcos de platino permite: i) mayor radiación solar incidente que favorece la patogenicidad de las bacterias y ii) mayor dispersión del inóculo a causa de la lluvia dentro de las plantas (Ocampo y Wyckhuys, 2012). En la inspección de Tapias (Ibagué) se encontró que la incidencia para la mancha de aceite, roña y marchitez vascular fue inferior al $4 \%$ (Figura 4), debido probablemente a que la mayoría de los cultivos no sobrepasan los 1.5 años, encontrándose al inicio de la etapa productiva. Esto ocasionó una baja densidad 
de inóculo inicial en el ambiente y bajos niveles de severidad (Goto, 1990; Mengesha \& Yetayew, 2018).

Con relación a la marchitez vascular, la enfermedad diezmó los cultivos de gulupa en Santa Isabel, haciendo poco viable la permanencia de los productores de este municipio en esta actividad agrícola. En Cajamarca, Casabianca y Rovira, municipios que presentan incidencias entre el $5 \%$ al
$10 \%$, se hace necesario implementar con mayor rigor las prácticas de prevención de la enfermedad, debido a que, una vez establecido el hongo (Fusarium oxysporum) en el suelo, su control requiere de la adopción conjunta de prácticas de manejo biológica, culturales y químicas de permanencia rigurosa en el tiempo. Estas prácticas tienen el propósito de disminuir la población del hongo mediante la creación de condiciones adversas para su desarrollo.

\section{CONCLUSIONES}

La sostenibilidad del agronegocio de la gulupa, en regiones productoras del departamento de Tolima, está supeditada a la tecnificación del cultivo y al empleo de buenas prácticas agrícolas que permitan la obtención de fruta con calidad de exportación, haciendo viable la rentabilidad económica del cultivo. Un adecuado sistema de riego por goteo, cubierta de semitecho, uso de fosa fitosanitaria, análisis de suelos y desinfección de herramientas son características que se relacionan con incidencias bajas de enfermedades, en especial de la secadera, en municipios con alta producción, como es el caso de Casabianca. La adopción de estas estrategias de tecnificación y BPA por los productores de gulupa constituyen uno de los principales desafíos de los sistemas de pequeña escala del departamento, en especial en los municipios de Rovira y Santa Isabel.

\section{CONTRIBUCIÓN DE LA AUTORÍA}

Primer autor: elaboración del proyecto, supervisión de la ejecución de la investigación en campo (metodología), conceptualización, redacción y corrección de la versión final del artículo. Segundo autor: ejecución de la investigación en campo, recolección de la información, realización de los análisis estadísticos (análisis de datos) y redacción de la versión final del artículo. Tercer y cuarto autor: ejecución de la investigación en campo, recolección de la información y procesamiento, realización de los análisis estadísticos y redacción de la versión inicial del artículo.

\section{AGRADECIMIENTOS}

Los autores agradecen al Ministerio de Agricultura y Desarrollo rural por la financiación de esta investigación con recursos del convenio TV19. El proyecto de investigación se denominó: "Estrategias de prevención de enfermedades limitantes de las pasifloras (gulupa y granadilla) en Colombia"
(ID 1000573). También agradecemos a los técnicos de campo de Corpoyarumos, Umata de Casabianca, y a los productores de gulupa de los municipios donde se realizó esta investigación.

\section{LITERATURA CITADA}

Agudelo, L. C. (2019). Fortalecimiento del área técnica y de mercados a unidades productivas de gulupa (Passiflora edulis sims) en el municipio de Duitama bajo el enfoque de cadena de valor [Tesis de pregrado, Universidad pedagógica y tecnológica de Colombia]. Repositorio institucional. https://repositorio.uptc.edu.co/ bitstream/001/2813/1/TGT_1417.pdf

Andersen, E., Elbersen, B., Godeschalk, F. \& Verhoog, D. (2007). Farm management indicators and farm typologies as a basis for assessments in a changing policy environment. Journal of Environmental Management, 82(3), 353-362. https://doi. org/10.1016/j.jenvman.2006.04.021

Angulo, R. (2009). Gulupa (Passiflora edulis var. edulis Sims). Bayer CropScience. 
Benítez, S. V. (2010). Caracterización del agente etiológico de la enfermedad denominada "mancha de aceite" en cultivos de gulupa (Passiflora edulis Sims) en zonas productoras de Colombia. [Tesis de maestría, Universidad Nacional de Colombia]. Repositorio institucional. https://repositorio.unal.edu.co/ bitstream/handle/unal/6844/186284.2010. pdf? sequence $=1$ \&isAllowed $=y$

Benítez, S. y Hoyos, L. (2009). Sintomatología asociada a bacteriosis en zonas productoras de gulupa (Passifora edulis Sims.) en Colombia. Revista colombiana de ciencias hortícolas, 3(2), 276-280. https:// doi.org/10.17584/rcch.2009v3i2.1218

Chacón, C. (1995). Fertilización del maracuyá. En R. Guerrero (Ed.), Fertilización de cultivos en clima medio (2a ed.) (pp. 187192). Monómeros Colombo Venezolanos. http://www.monomeros.com/descargas/ dpmanualmedio.pdf

Correa, E., Araméndiz, H., Azeredo, L., Pombo, C. y Cardona Ayala, C. E. (2010). Tipificación de comercializadores de berenjena en zonas productoras del Caribe Colombiano. Temas Agrarios, 15(2), 46-57. https://doi.org/10.21897/rta.v15i2.679

Costa, A. P., Nogueira, I., Peixoto, J. R., Blum, L. E. B., Vilela, M. S. \& Vendrame, W. (2018). Reaction of yellow passion fruit to passion fruit woodiness disease and to bacterial spot. Bioscience Journal, 34(6), 189-196. https://doi.org/10.14393/B]v34n6a2018-39686

Da Silva, A. C. R., Ferro, J. A., Reinach, F. C., Farah, C. S., Furlan, L. R., Quaggio, R. B., Monteiro-Vitorello, C. B., Van Sluys, M. A., Almeida, N. F., Alves, L. M. C., Do Amaral, A. M., Bertolini, M. C., Camargo, L. E. A., Camarotte, G., Cannavan, F., Cardozo, J., Chambergo, F., Ciapina, L. P., Cicarelli, R. M. B ... Kitajima, J. P. (2002). Comparison of the genomes of two Xanthomonas pathogens with differing host specificities. Nature, 417(6887), 459-463. https://doi.org/10.1038/417459a

Deshmukh, N., Patel, R., Okram, S., Banga, U., Vishwavidyalaya, K. \& Rymbai, H. (2017). Passion fruit (Passiflora spp.). En S. Ghosh, A. Singh \& A. Thakur (Eds.),
Underutilized fruit crops: importance and cultivation ( pp. 979-1005). Narendra Publications. https://www. researchgate.net/ publication/312033241_Underutilized_Fruit_ Crops_Importance_Cultivation

Dhawan, K., Dhawan, S. \& Sharma, A. (2004). Passiflora: A review update. Journal of Ethnopharmacology, 94(1), 1-23. https:// doi.org/10.1016/j.jep.2004.02.023

Di Rienzo, J. A., Macciavelli, R. E. y Casanoves, F. (2012). Modelos Lineales Mixtos: aplicaciones en InfoStat. https://www. researchgate.net/publication/283491350_ Modelos_lineales_mixtos_aplicaciones_en_ InfoStat

Escobar, G. y Berdegué, J. (1990). Conceptos y metodología para la tipificación de sistemas de finca: la experiencia de RIMISP. En G. Escobar y J. Berdegué (Eds.), Tipificación de sistemas de producción agrícola. (pp. 13-44). Rimisp.

Escobar, N., Romero, N. J. \& Jaramillo, C. I. (2019). Typology of small producers in transition to agroecological production. Agronomy Research, 17(6), 2242-2259. https://doi.org/10.15159/AR.19.221

Fischer, I. \& Rezende, J. A. M. (2008). Diseases of passion flower (Passiflora spp.). Pest Technology, 2(1), 1-19.

Fischer, G. (2010). Condiciones ambientales que afectan crecimiento, desarrollo y calidad de las pasifloráceas. En M. Parra, C. Carranza, J. Cárdenas, y D. Miranda (Eds.), Memorias: Primer congreso Latinoamericano de Passiflora (pp. 10-22). Corporación Centro de Investigación para la gestión Tecnológica de Passiflora del departamento del Huila. https://studylib.es/ doc/7309886/memorias-primer-congresolatinoamericano-de-passiflora

Guilherme, A., Ferreira, L., De Luna, A. G., Pereira, A. C., Lima, D., Pereira, A. P. \& Cola, J. (2020). Physiology and production of yellow passion fruit with hydroabsorbent polymer and different irrigation depths. Revista Ceres, 67(5), 365-373. https://doi. org/10.1590/0034-737X202067050004 
Goto, M. (1990). Fundamentals of Bacterial Plant Pathology. Academic Press. https:// books.google.com.co/books? id=js3lpMiU-zU $C \& p g=P A 177 \& l p g=P A 177 \& d q=l o w+$ inoculu $\mathrm{m}+$ plant + age + bacteria\&source $=$ bl\&ots $=S 6-$ flbEajU\&sig=ACfU3U2JsWSx4vW9tzreWYbf ug_KxARF8w\&hl=es-419\&sa $=X \& v e d=2 a h U$ KEwizvN780qrqAhWJc98KHfprAGIQ6AEwD 3oECAsQAQ\#v=onepage \& $\mathrm{q}=$ low inoculum plant age bacteria\&f=false https://www. sciencedirect.com/book/9780122934650/ fundamentals-of-bacterial-plant-pathology

Guto, S. N., Pypers, P., Vanlauwe, B., De Ridder, N. \& Giller, K. E. (2012). Socioecological niches for minimum tillage and crop-residue retention in continuous maize cropping systems in smallholder farms of central Kenya. Agronomy Journal, 104(1), 188-198. https://doi.org/10.2134/ agronj2010.0359

Harrington, L. W. \& Tripp, R. (1984). Recommendation Domains: A Framework for On-Farm Research. CIMMYT.

Hernández-Castellano, L. E., Nally, J. E., Lindahl, J., Wanapat, M., Alhidary, I. A., Fangueiro, D., Grace, D., Ratto, M., Bambou, J. C. \& De Almeida, A. M. (2019). Dairy science and health in the tropics: challenges and opportunities for the next decades. Tropical Animal Health and Production, 51(5), 10091017. https://doi.org/10.1007/s11250-01901866-6

\section{Instituto Nacional de Estadística y Geografía. (2013). Características edafológicas, fisiográficas, climáticas e} hidrográficas de México. Instituto Nacional de Estadística y Geografía. https://www. rua.unam.mx/portal/recursos/ficha/18641/ caracteristicas-edafologicas-fisiograficasclimaticas-e-hidrograficas-de-mexico

Jiménez, J., Aranda, Y. \& Darghan, E. (2017). Typification of the production system of snuff (Nicotiana tabacum) in the Guanenta province, Santander department, Colombia. Agronomía Colombiana, 35(2), 247-255. https://doi.org/10.15446/agron.colomb. v35n2.63972

Jiménez, Y., Carranza, C. \& Rodríguez, M. (2009). Manejo Integrado de la gulupa
(Passiflora edulis Sims). En D. Miranda, G. Fischer, C. Carranza, S. Magnitskiy, F. C, W. P y L. E. Flórez (Eds.), Cultivo, poscosecha y comercialización de las pasifloráceas en Colombia: maracuyá, granadilla, gulupa y curuba (pp. 159-190). Sociedad Colombiana de Ciencias Hortícolas. http://fedepasifloras. org/es/wp-content/uploads/2018/01/ Cultivo-poscosecha-y-comercialización-delas-pasifloráceas-en-Colombia.pdf

Joy, P. P. \& Sherin, C. G. (2016). Diseases of Passion Fruit (Passifora edulis) and their Management. En A. Kumar \& P. Mall (Eds.), Insect Pests Management of Fruit Crops (pp. 453-470). Biotech. https://www. researchgate.net/publication/306034959

Köbrich, C., Rehman, T. \& Khan, M. (2003). Typification of farming systems for constructing representative farm models: Two illustrations of the application of multi-variate analyses in Chile and Pakistan. Agricultural Systems, 76(1), 141-157. https://doi. org/10.1016/S0308-521X(02)00013-6

Kraiselburd, I., Moyano, L., Carrau, A., Tano, J. \& Orellano, E. G. (2017). Bacterial Photosensory Proteins and Their Role in Plant-pathogen Interactions. Photochemistry and Photobiology, 93(3), 666-674. https:// doi.org/10.1111/php.12754

Lê, S., Josse, J. \& Husson, F. (2008). FactoMineR: An $\mathrm{R}$ package for multivariate analysis. Journal of Statistical Software, 25(1), 1-18. https://doi.org/10.18637/jss. v025.i01

Lüdders, P. (2003). Granadilla (Passifora edulis Sims) - A multiple useful tropical fruit. Erwerbs-Obstbau, 45(6), 186-191. https://www.researchgate. net/publication/288319314_Gr anadilla _Passiflora_edulis_Sims_-_A_multiple_ useful_tropical_fruit

Ministerio de Agricultura y Desarrollo Rural. (2018). Evaluaciones Agropecuarias Municipales. Ministerio de Agricultura y Desarrollo Rural. https://www.agronet.gov. co/estadistica/Paginas/home. aspx ?cod $=1$

Ministerio de Agricultura y Desarrollo Rura. (2019). Área, Producción y Rendimiento 
Nacional por Cultivo/Gulupa. https://www. agronet.gov.co/estadistica/Paginas/home. aspx?cod $=1$

Mengesha, G. G. \& Yetayew, H. T. (2018). Distribution and association of factors influencing bean common bacterial blight (Xanthomonas axonopodis pv. phaseoli) epidemics in Southern Ethiopia. Archives of Phytopathology and Plant Protection, 51(1920), 1066-1089. https://doi.org/10.1080/03 235408.2018.1551043

Miranda, D. y Carranza, C. (2010). Caracterización de sistemas productivos de pasifloráceas en Colombia. En M. Parra, C. Carranza, J. Cárdenas y D. Miranda (Eds.), Memorias: Primer congreso Latinoamericano de Passiflora (pp. 27-59). Corporación Centro de Investigación para la gestión Tecnológica de Passiflora del departamento del Huila. https://studylib.es/doc/7309886/memoriasprimer-congreso-latinoamericano-depassiflora

Miranda, D., Fischer, G., Carranza, C., Magnitskiy, S., Cassierra, F., Piedrahíta, W. y Flórez, L. E. (Eds.). (2009). Cultivo, poscosecha y comercialización de las pasifloráceas en Colombia: maracuyá, granadilla, gulupa y curuba. Sociedad Colombiana de Ciencias Hortícolas.

Montoya-Estrada, C. N., Castaño-Zapata, J. y Villegas-estrada, B. (2013). Evaluación de alternativas de manejo de la bacteriosis del maracuyá. Acta Agronómica, 21(2), 40-50. http://agronomia.ucaldas.edu.co/ downloads/Agronomia21(2)_5.pdf

Mora, R. (2011). Análisis epidemiológico de roña en gulupa (Passiflora edulis Sims.) en la región del Sumapaz, Colombia. Universidad Nacional de Colombia.

Moreira, R., Cruz, M., Santos, A., Fernandes, D., \& Oliveira, J. (2017). Production viability of passion fruit at high planting density in Jequitinhonha valley, Minas Gerais, Brazil. Bioscience Journal, 33(4), 843-849. https:// doi.org/10.14393/BJ-v33n4a2017-36680

Murtagh, F. \& Legendre, P. (2014). Ward's Hierarchical Agglomerative Clustering
Method: Which Algorithms Implement Ward's Criterion? Journal of Classification, 31, 274295. https://doi.org/10.1007/s00357-0149161-z

Nakasone, H. Y. \& Paull, R. E. (1998). Tropical fruits. CAB INTERNATIONAL.

Ocampo, J., Posada, P., Medina, J., Jarvis, A. y Van Zonnelveld, M. (2010). Definición de zonas agroecológicas para mejorar los sistemas de producción del maracuyá (Passiflora edulis $f$. flavicarpa), granadilla (Passiflora ligularis Juss.) y gulupa (Passiflora edulis Sims.) en Colombia. En M. Parra, C. Carranza, J. Cárdenas y D. Miranda (Eds.), Memorias: Primer Congreso Latinoamericano de Passiflora (pp. 60-61). Corporación Centro de Investigación para la Gestión Tecnológica de Passiflora del departamento del Huila. https://studylib.es/doc/7309886/memoriasprimer-congreso-latinoamericano-depassiflora

Ocampo, J. y Wyckhuys, K. (2012). Tecnología para el cultivo de la Gulupa en Colombia (Passiflora edulis $f$. edulis Sims): purple passion fruit. Universidad Jorge Tadeo Lozano

Osorio, J., Martínez, E., Clímaco, J., Aguirre, J., Vergara, J., Luque, N., Rojas, E. y Cruz, G. (2020). Caracterización sanitaria de los cultivos de granadilla, gulupa y maracuyá en Colombia, con especial referencia a la secadera causada por Fusarium solani $f$. sp. passiflorae. Agrosavia. https://doi.org/10.21930/agrosavia. investigation.7403381

Aguacate, uchuva y gulupa, con potencial exportador (2020, febrero 6). Portafolio. https://www.portafolio.co/economia/ aguacate-uchuva-y-gulupa-con-potencialexportador-537868

Prieto, D. (2019). La tecnificación como herramienta para incrementar la productividad agropecuaria en Colombia. Fundación Universidad de América.

Ramírez, J., Tamayo, P., \& Morales, J. (2017). Identification and pathogenicity of microorganisms affecting purple passion 
fruit in Colombia. Revista Ceres, 64(3), 250-257. https://doi.org/10.1590/0034737X201764030005

Rodríguez, N. C., Melgarejo, L. M., \& Blair, M. W. (2019). Purple Passion Fruit, Passifora edulis Sims f. edulis, Variability for Photosynthetic and Physiological Adaptation in Contrasting Environments. Agronomy, 9(5). https://doi.org/10.3390/agronomy9050231

Santos, V., Zúñiga, J. y Santos, C. (2013). Tipificación de productores agropecuarios: Estudio de caso en la Región Texcoco del Estado de México. Universidad Autónoma Chapingo. https://www.researchgate.net/
publication/327424645_Tipificacion_de productores_agropecuarios_Estudio_de_ caso_en_la_Region_Texcoco_del_Estado_ de_Mexico

Toro-Mujica, P., Aguilar, C., Vera, R., Rivas, J. \& García, A. (2015). Sheep production systems in the semi-arid zone: Changes and simulated bio-economic performances in a case study in Central Chile. Livestock Science, 180, 209-219. https://doi.org/10.1016/j. livsci.2015.07.001

\section{Conflicto de intereses}

Los autores declaran no tener ningún conflicto de intereses. 
